UCRL-ID-129943

\title{
Rapid Tooling by Electron-Beam Vapor Deposition
}

\author{
T. M. Anklam, J. Jancarik, T. C. Meier, \\ D. G. Braun, T. A. Shepp
}

February 25, 1998

This is an informal report intended primarily for internal or limited external distribution. The opinions and conclusions stated are those of the author and may or may not be those of the Laboratory.

Work performed under the auspices of the U.S. Department of Energy by the Lawrence Livermore National Laboratory under Contract W-7405-Eng-48. 


\section{DISCLAIMER}

This document was prepared as an account of work sponsored by an agency of the United States Government. Neither the United States Government nor the University of California nor any of their employees, makes any warranty, express or implied, or assumes any legal liability or responsibility for the accuracy, completeness, or usefulness of any information, apparatus, product, or process disclosed, or represents that its use would not infringe privately owned rights. Reference herein to any specific commercial product, process, or service by trade name, trademark, manufacturer, or otherwise, does not necessarily constitute or imply its endorsement, recommendation, or favoring by the United States Government or the University of California. The views and opinions of authors expressed herein do not necessarily state or reflect those of the United States Government or the University of California, and shall not be used for advertising or product endorsement purposes.

This report has been reproduced directly from the best available copy.

Available to DOE and DOE contractors from the Office of Scientific and Technical Information

P.O. Box 62, Oak Ridge, TN 37831

Prices available from (615) 576-8401, FTS 626-8401

Available to the public from the

National Technical Information Service

U.S. Department of Commerce

5285 Port Royal Rd.,

Springfield, VA 22161 


\title{
Rapid Tooling by Electron-Beam Vapor Deposition
}

\author{
T.M. Anklam, J. Jancarik, T.C. Meier, D.G. Braun, and T.A. Shepp
}

\section{SUMMARY}

Electron-beam physical vapor deposition (EBPVD) of tooling metal, onto a shaped substrate to produce a replica of the substrate surface, offers the potential for significant cost savings over present methods of injection mold manufacturing. These savings are realized by the high deposition rate and the corresponding short manufacturing times provided by the EBPVD process. However, on route to realizing these gains, there are process technical issues which need to be resolved. Mold surfaces typically contain relatively high aspect ratio details that must be replicated to dimensional tolerances within +/- 2 mils. The deposited mold material must also provide high surface hardness and high fracture toughness. Good quality grain structure can be obtained in deposited $\mathrm{Al} 10-\mathrm{wt} \%$ $\mathrm{Cu}$ mold material when the substrate and corresponding deposit are at high process temperature. However, the resulting mold is subject to distortion during cooldown due to differential temperatures and shrinkage rates. Thermally controlled cooldown and the use of crushable substrate materials reduce these distortions, but not to the required levels of tolerance. Deposition of the Al-Cu at lower temperature produces columnar, poorly joined grains which result in a brittle and weakened mold material. When $\mathrm{Al} 10-\mathrm{wt} \% \mathrm{Cu}$ metal vapor is deposited across high aspect ratio step features on the substrate surface, a grain growth defect can form in the step-shadowed regions of the deposited material, alongside the step feature. The step coverage defect consists of entrained voids which persist at intermediate deposition temperatures and produce a weakened mold. This final 1997 LDRD report investigates causes of this step coverage defect and offers methods for their control and elimination.

\section{INTRODUCTION}

This is the final 1997 LDRD report on the development of the electron-beam physical vapor deposition (EBPVD) process as a means for the production of injection molds for the mass production of molded plastic parts.

Prior to this year's investigations, the EBPVD process had been demonstrated as a means for producing near net-shape $\mathrm{U} 6-\mathrm{wt} \% \mathrm{Nb}$ test parts and $\mathrm{\Lambda l} 10-\mathrm{wt} \% \mathrm{Cu}$ tooling for mold applications. The vapor deposited $\mathrm{Al}-\mathrm{Cu}$ alloy has demonstrated comparable mechanical and physical properties to the same alloy processed by conventional forming and machining methods. The vapor deposited $\mathrm{Al} \mathrm{10-wt \%} \mathrm{Cu}$ has a measured yield strength of $25 \mathrm{ksi}$, ultimate strength of $52 \mathrm{ksi}$ and a C Rockwell hardness of 25-30. This alloy typically exhibits high fracture toughness.

The physical properties that apply to the EBPVD manufacture of replica mold shapes include: vapor pressures of elemental alloy constituents, thermal conductivity of substrate and alloy, CTE (coefficient of thermal expansion), elastic modulus and yield strength of substrate and alloy, chemical compatibility of substrate and alloy and any hazardous properties exhibited by any selected process materials. The Al-Cu alloy meets EB process requirements and has been demonstrated as a workable material for EBPVD injection mold manufacture process development. 
The primary issue facing the use of the EBPVD process for mold manufacture is the management of part distortions. Distortions occur during cooldown of the part and substrate from process temperature to room temperature. Deposition process temperatures are typically $600-850^{\circ} \mathrm{C}$, with greater distortion associated with higher temperature and poorer grain structure associated with lower temperature. Thermal gradients within the substrate and part, differences in deposition thickness on substrate surfaces, variations in thermal conductivity between substrate and part, and other process variables make the minimization of part distortion a technically difficult issue to resolve.

Another aspect of part distortion evolves from the stresses created in the vapor deposited part by the substrate during cooldown. Thermally induced stresses and resulting strains can be attributed to non-matching CTE (coefficient of thermal expansion). The different CTE, yield stress and elastic modulus of the substrate and the vapor deposited material which conforms to the substrate, cause them to flex like a bimetallic strip and distort to cancel net residual stresses. Tests were conducted during FY 1996 to determine effects of matching CTE on distortion. A flat test substrate was designed that employed tapered grooves of varying depth to provide fiducials for measuring planar distortion. It was found that despite an almost ideal match in CTE between part (Al-Cu) and substrate (304SS), the part and substrate did not separate on cooldown. It should be noted that a thin boron nitride film $(<0.003$ ') has been routinely applied to substrates in all previous tests to provide a non-reactive parting surface between part and substrate. A crushable boron nitride (BN) substrate of the same geometry was tested which produced more favorable results. The substrate conformed to the vapor deposited part but separated cleanly after cooldown and a smooth surface finish was achieved. However, required levels of dimensional tolerance were not achieved. Distortion was reduced from 15 mils (with a graphite substrate) to 12 mils (with a BN substrate).

During these tests, a more fundamental, but related, issue was identified. When the $\mathrm{Al}-\mathrm{Cu}$ vapor is deposited across the tapered grooves of the substrate surface, a grain growth defect forms, more so at reduced temperatures $\left(<750^{\circ} \mathrm{C}\right)$, in the vapor-shadowed regions alongside the grooves. These regions, where vapor coverage is partially blocked by the leading edge of the groove, contain grain structures ranging from poorly interconnected columnar growth to equiaxed growth with entrained voids. The defect is oriented along the shadowed edge of the groove. This oriented weakness in the part produces localized strain of the part during cooldown. Achieving control of the step coverage defect is a prerequisite to controlling cooldown induced distortions in the vapor deposited parts and as a result, became the prime focus of FY 97 efforts.

To assess the step coverage issue, we developed a conceptual model for step coverage defect formation. The direction and distribution of vapor projected onto a substrate surface is defined by the expansion of evaporant alloy from the vapor source to the substrate. At reduced deposition temperature, vapor that impinges normal to the substrate surface can typically form a fully dense deposit. Vapor which intersects step edges produces a shock wave along that edge which introduces vapor scattering immediately beyond the intersecting edge. The step causes a discontinuity in the projected vapor coverage, which produces a deposition coverage gap that can result in captured voids within the deposited material. However, after vapor settles on a substrate surface, it can be further transported across the surface by thermally activated surface diffusion. Likewise, deposited material can move within the deposited material by thermally activated bulk diffusion. If surface and bulk diffusion coefficients are high enough, surface gaps and defects can fill and bulk voids can coalesce to minimize free energies within the deposited mass. The extent to which diffusion mechanisms rearrange deposited material is dependent on process temperature, time at process temperature and the self diffusion properties of the deposited material. 
Given this model, we then defined an experiment to allow some decoupling of process temperature, substrate geometry, vapor impingement and thermally dependent diffusion effects. A test apparatus was designed to minimize vapor shadowing and process temperature variation effects. The previously used tapered grooved test substrate was employed to provide a common basis for deposition evaluation. Finally, unalloyed $\mathrm{Cu}$ was chosen as a evaporant to provide a deposition material with well defined diffusion properties.

\section{EXPERIMENT}

The following experiment was conducted to assess the step coverage defect by evaluating the limiting case where substrate manipulation and thermal control minimize geometric and thermal effects on vapor deposition and unalloyed $\mathrm{Cu}$ is evaporated to allow characterization of diffusion effects at nominal deposition temperature for this well characterized primary constituent of the Al-Cu alloy .

An assembly drawing of the experimental apparatus is shown in Figure 1. The apparatus provided substrate manipulation within the projected vapor stream to control deposition thickness and vapor impingement angle across the substrate surfaces. An assembly of radiant heat shields and heater elements surrounded the substrate and manipulator to control substrate temperature and to minimize thermal variations within this thermal zone. A graphite test substrate of tapered groove geometry was used in this experiment to allow comparison of test results to those of earlier tests. A bottom fed water cooled crucible provided continuous feed of a three inch diameter low oxygen copper bar. Feed rate was closed loop controlled via video image processing to replenish evaporated copper by maintaining pool level in the crucible. The molten pool region at the top of the bar was heated by a magnetically steered $5 \mathrm{~mm}$. diameter spot electron beam that was swept in a one inch circular pattern at $8 \mathrm{kHz}$ sweep frequency to provide a continuous beam power of $40 \mathrm{~kW}$.

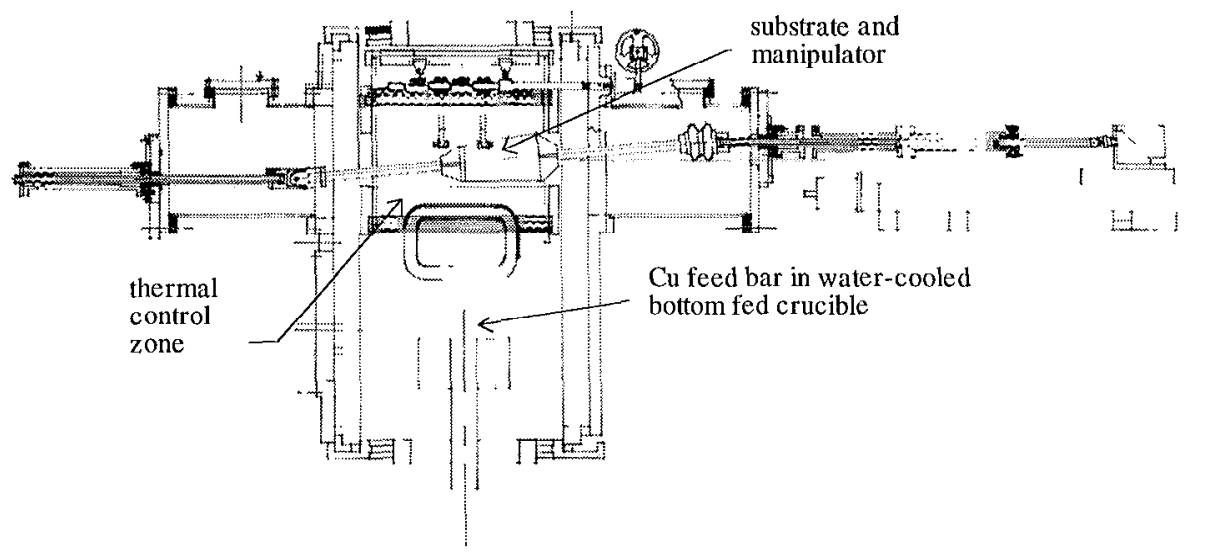

Figure 1

Test apparatus, including substrate, manipulator, thermal control zone and bottom fed crucible with copper feed bar 
The test plan called for continuous evaporation of copper onto the manipulated test substrate while maintaining thermal zone temperature at $600^{\circ} \mathrm{C}$ throughout the deposition process. This temperature represents an optimum, chosen to minimize thermal distortion at cooldown while still providing active diffusion in the material. After evaporation of 17.5 kilograms of copper feed, e-gun power is turned off and the thermal zone is allowed to cool to room temperature while under vacuum. Previous checkout tests of the experimental apparatus had determined the cooldown rate to be on the order of $2^{\circ} \mathrm{C}$ per minute. Following cooldown, the apparatus is photographed and disassembled. The part separated from the substrate was to be macro-photographed, measured for distortion and sectioned. Sections were to be examined for defects.

\section{RESULTS}

The plot of e-gun emission current in Figure 2, and corresponding substrate temperature in Figure 3, provide a good indication of the successes and problems encountered during this vapor deposition experiment. The experiment ran for 9.4 hours, incidentally producing $18.7 \mathrm{~kg}$. of copper evaporant at a nominal average vaporization rate of $2 \mathrm{~kg} / \mathrm{hr}$. The part was rotated $+/-20^{\circ}$ with a cyclic period of 300 seconds. The part temperature was maintained at $625^{\circ} \mathrm{C}\left(+/-12^{\circ} \mathrm{C}\right)$ for $50 \%$ of the run. However, during the balance of run time, the indicated part temperature was beyond these bounds. The primary source of substrate temperature excursions were interruptions in e-beam power caused by e-gun arcing. As a result, substrate temperature dropped during e-gun arcing episodes at 1100,1450 and 1600 hours. After 1600 hours, the part temperature does not return to the pre-arcing value and instead oscillates about $550^{\circ} \mathrm{C}$. The indicated temperature offset and oscillation after 1600 hours has not been explained and may not represent actual test conditions. The test run was completed at 1900 hours.

Figure 2 - Electron gun emission current vs. time

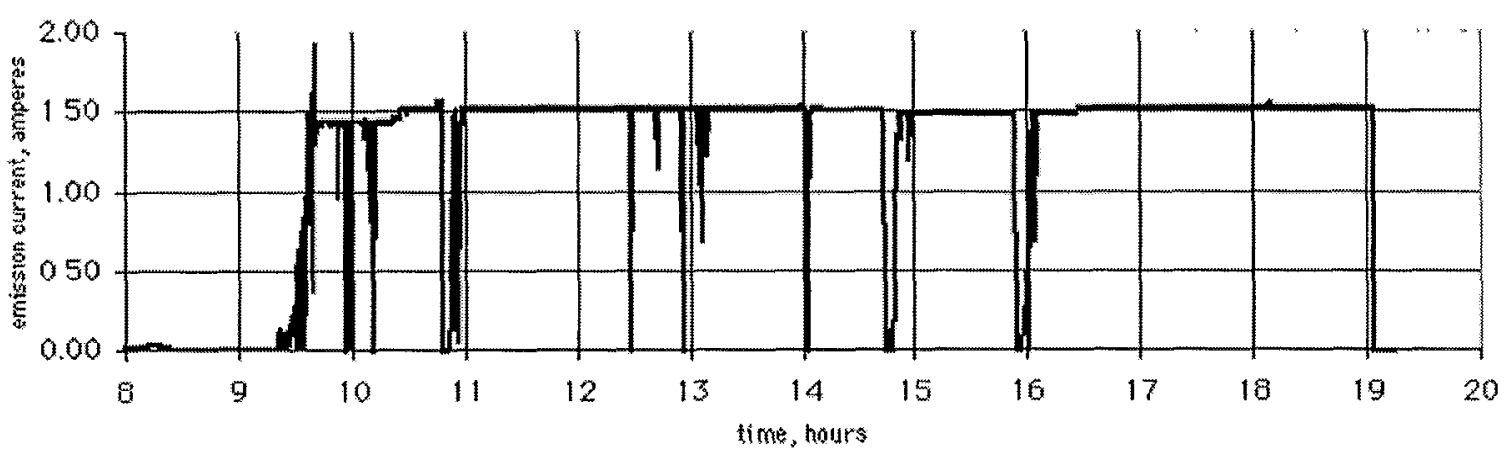


Figure 3 -. Substrate temperature vs, time

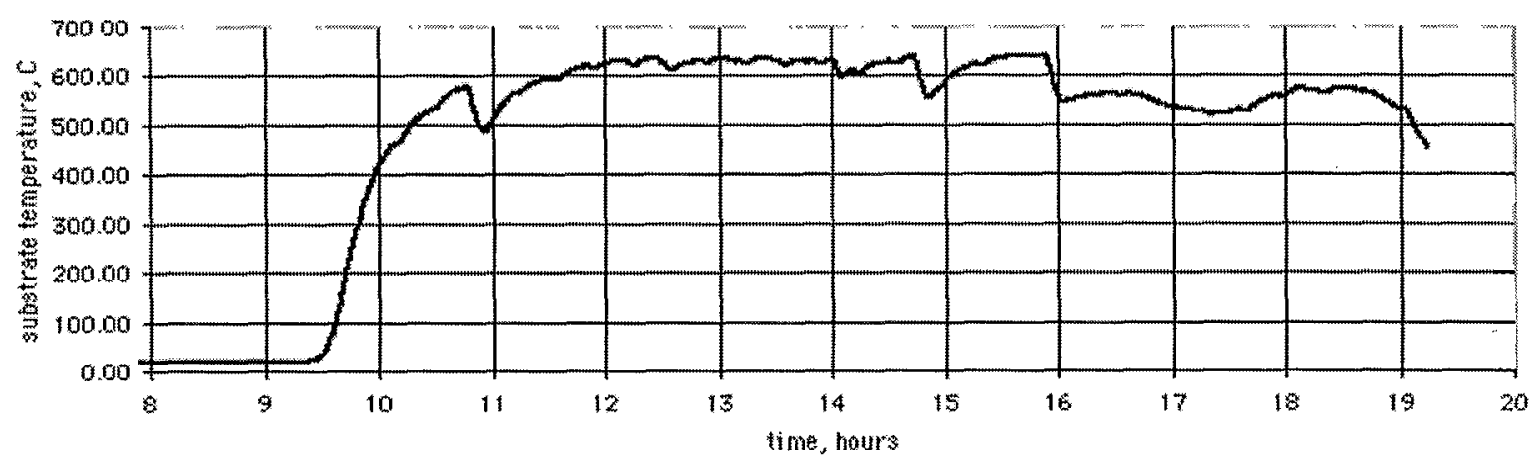

After an overnight cooldown of the test apparatus, the vacuum vessel was vented to atmosphere and opened for inspection. Figure 4 shows the deposited part and subatrate attached to the manipulator shaft, before disassembly.

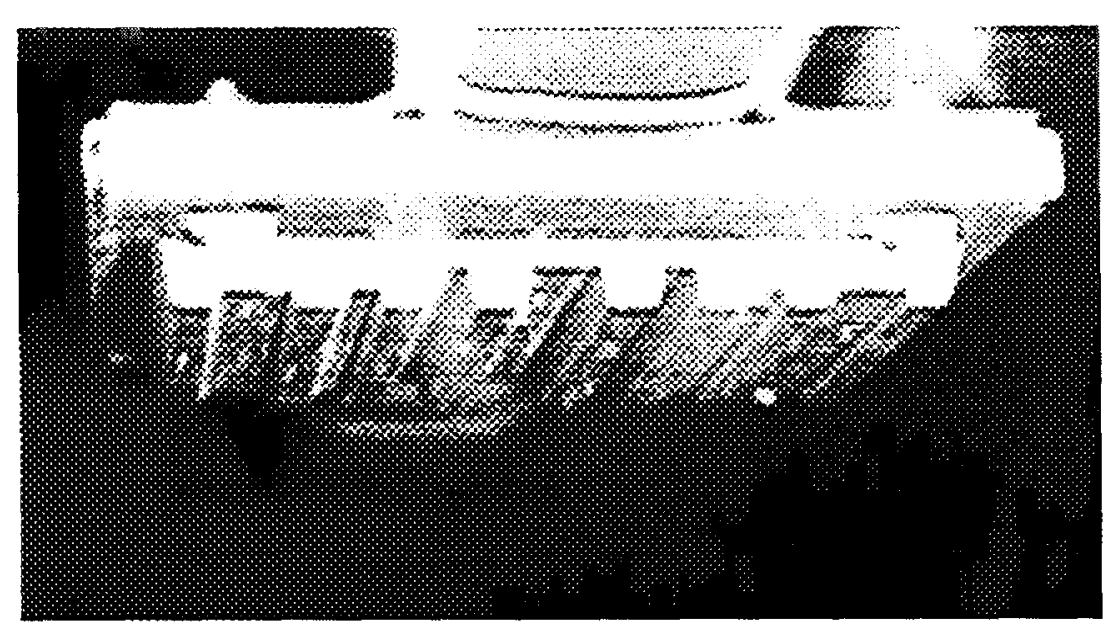

\section{Figure 4}

Vapor deposited copper part prior to disassembly

Following disassembly, the part was measured for distortion. Distortion is defined as the planar displacement of a location on the part relative to its corresponding location on the undistorted substrate surface. The outermost surface of the substrate defines the flat plane. This plane corresponds to the bottoms of the grooves of the replicated surface, as shown in Figure 5. 


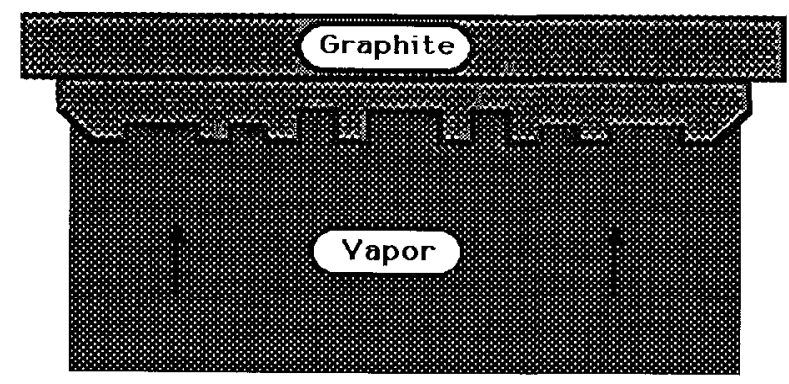

Ideal product:

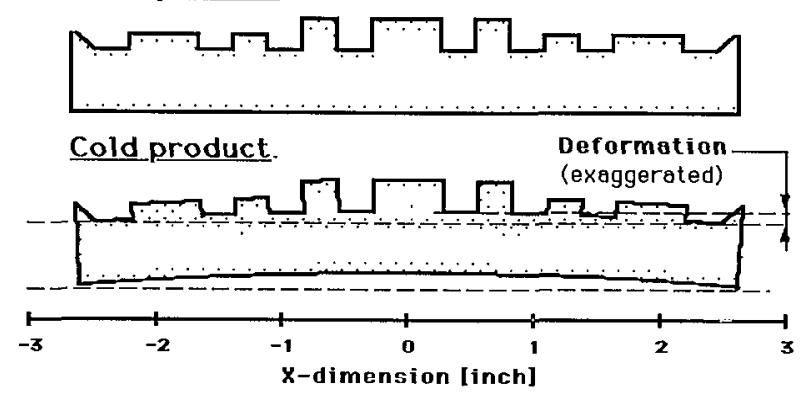

Figure 5

Schematic representation of substrate, part and uniform cooldown distortion Figure 6.

Measurements taken along lines perpendicular to the grooved features are plotted in
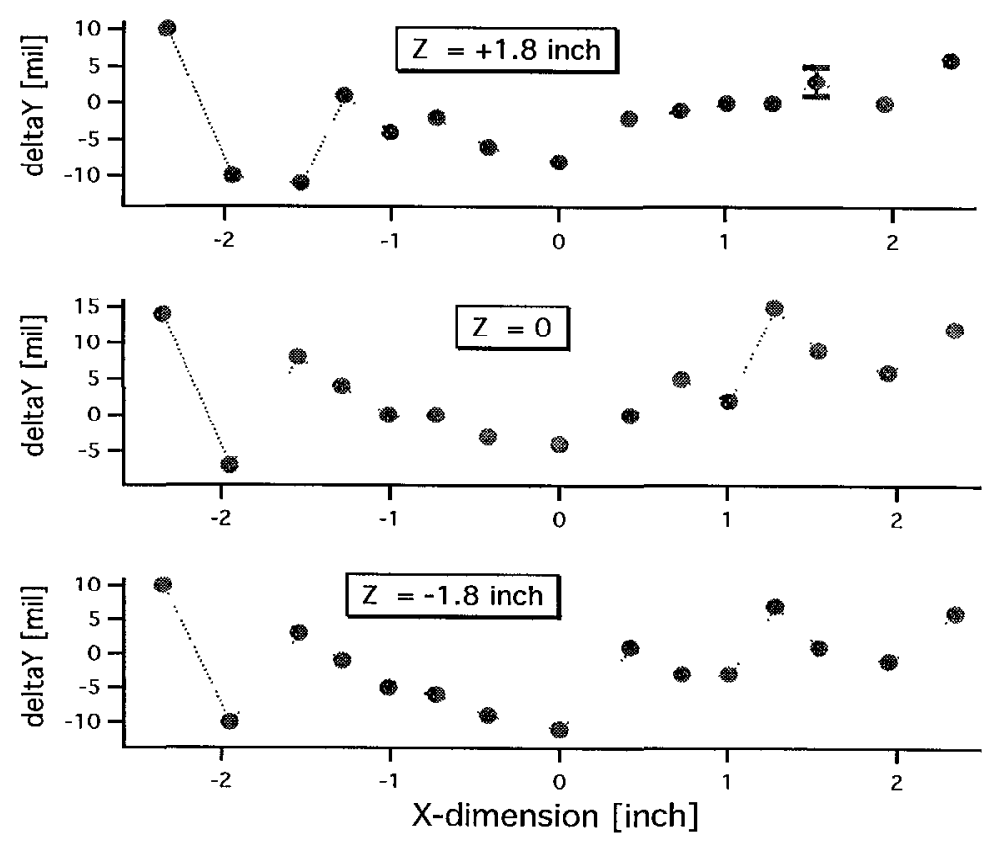

\section{Figure 6 \\ Measured distortions in copper test part}

The three trace measurements of part distortion show non-uniform distortion on the order of $+/-10$ mils. This amount of distortion is lower than in earlier tests, but still greater than the 2 mils specified as process requirements. 
The copper test piece was sectioned and polished to allow comparision of grain growth and defect structure with the earlier Al-Cu test piece. The micrographs in Figures 7 and 8 show a fully dense microstructure on the flat normal surfaces of both substrates. The $\mathrm{Cu}$ piece shows improved step coverage but persistence of the step coverage defect despite manipulation of the part during deposition with active diffusion.

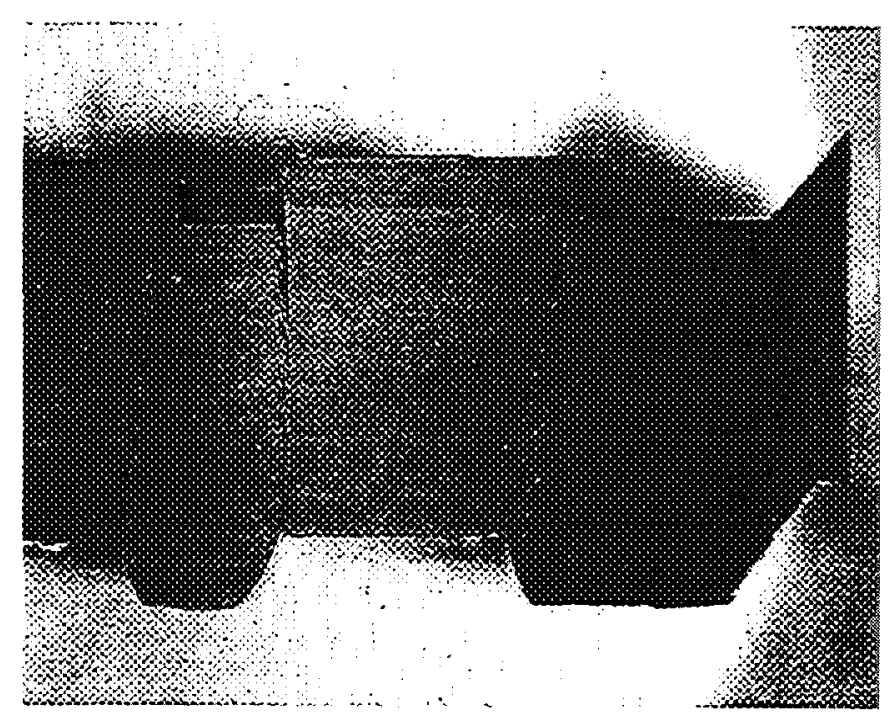

\section{Figure 7 \\ Al-Cu test piece showing significant step coverage defect}

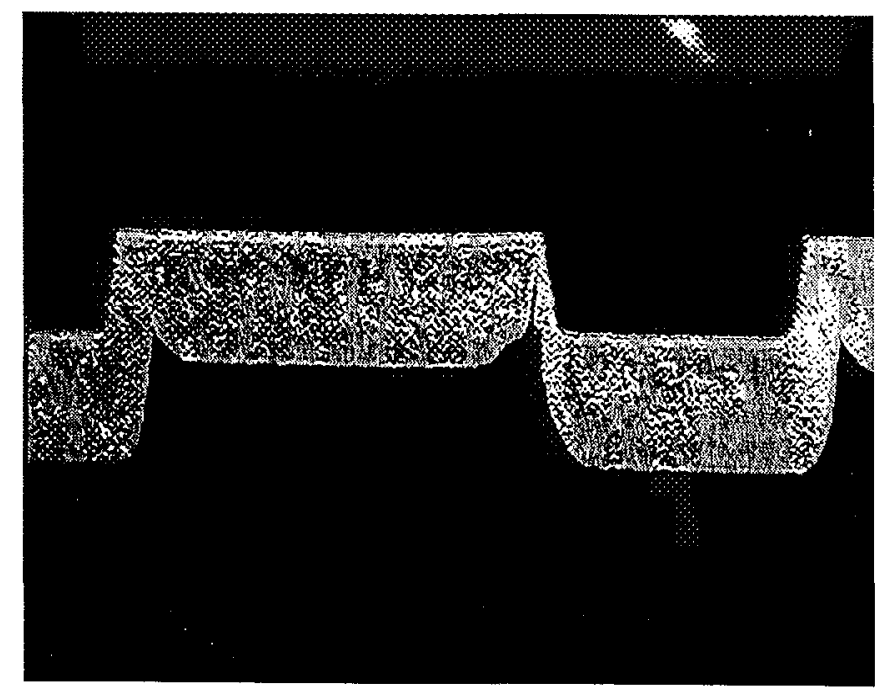

Figure 8

Copper test part showing improved coverage but persistent step defect 


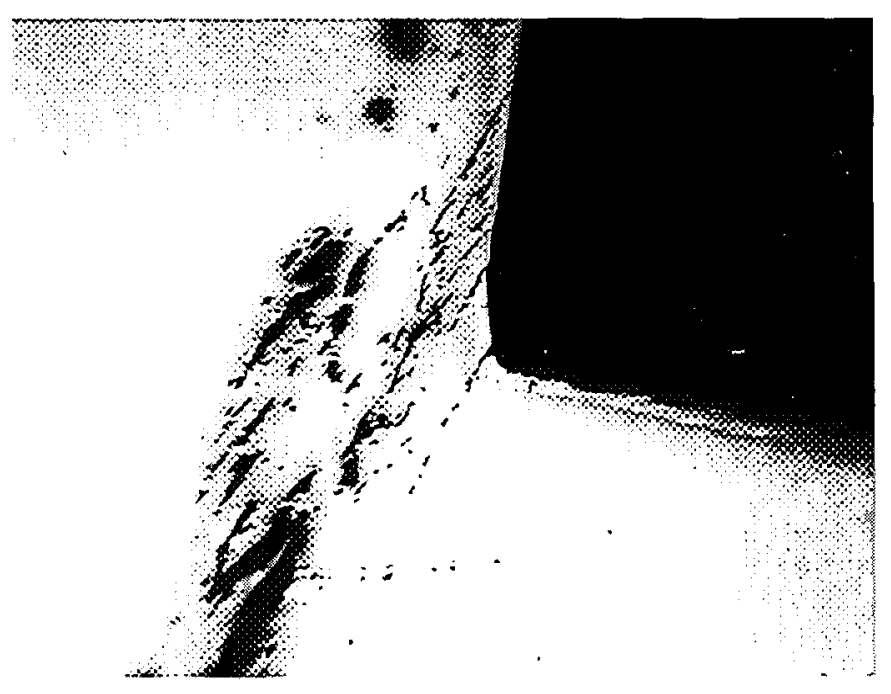

\section{Figure 9 \\ Micrograph showing coalescence of voids in the copper deposit along the step feature}

The 10X micrograph in Figure 9 shows some coalescence of entrained voids behind the shadowed edge of the substrate groove. The defect is of sufficient magnitude to provide localized weakness of the part and corresponding nonuniform part distortion during cooldown.

\section{DISCUSSION}

All of the process effects anticipated by the conceptual model of step coverage defect formation were demonstrated in this test, if not to the extent necessary to resolve the underlying step coverage problem. The counteracting effects of part distortion at high temperature and low diffusion rates and defect formation at low temperature, suggest that non-uniform part distortion may by optimized to an acceptable level for many rapid tooling applications but will not be eliminated by these methods.

\section{CONCLUSIONS}

The results of this test indicate that part manipulation and thermal control have a positive effect toward the reduction of step coverage defects by reducing the shadowing of vapor coverage across step features on a substrate surface and by maintaining desired deposition conditions. Diffusion mechanisms at process temperature play a role in defect reduction by allowing redistribution of deposited material through its bulk and across its surfaces, as evidenced by the coalescence of voids. However, their combined effects were not sufficient to eliminate the step coverage defect in this part. In this case, vapor deposition at reduced temperature minimized part distortion during cooldown, at the expense of thermally activated mass transport mechanisms for reducing bulk defects.

Another method for achieving rearrangement of vapor deposited metal atoms at the part surface utilizes ion assisted vapor deposition. Vapor ions are accelerated toward the voltage biased substrate to increase the deposition energy of the vapor atoms and improve their mobility on deposition. Future testing will focus on optimizing substrate temperature and part manipulation while using ion-assisted vapor deposition to achieve the acceptable microstructure, mechanical properties and dimensional tolerance of the finished part. 


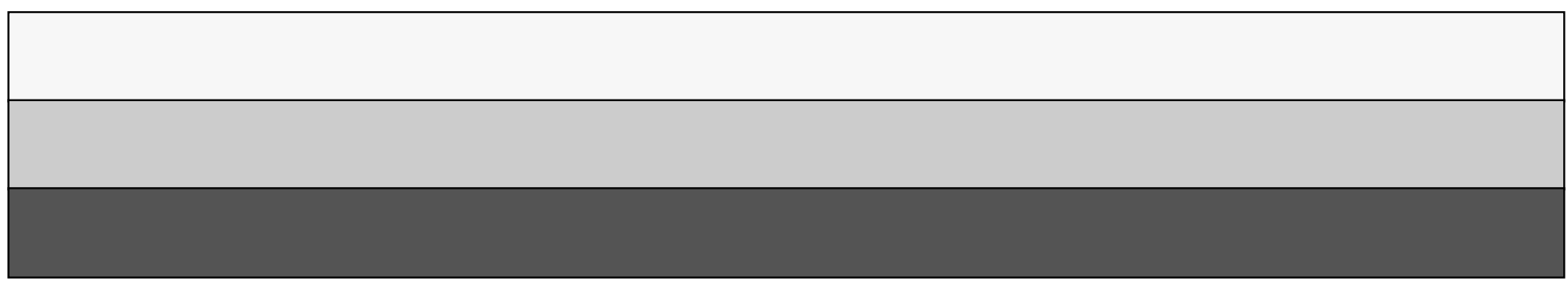

